\title{
Uniqueness of the Solution of àn Inverse Problem for a Quasilinear Parabolic Equation in Divergence Form
}

\author{
S. DüMmel and.S: HaNdrock-MeYeR
}

Es wird die quasilineare parabolische Differentialgleichung $u_{t}=\operatorname{div}(a(u) \operatorname{grad} u)$ mit einer konstanten Anfangsbedingung und einer Randbedingung 1. Art betrachtet, wobei a eine positive analytische Funktion von $u$ ist. Unter 'gewissen Zusatźvoraussetzungen bezüglich $u$ wird ein Eińdeutigkeitssatz für die Bestimmung des Koeffizienten a bewiesen.

Рассматривается квазилинейное параболическое дифференциальное уравнение $u_{t}^{\prime}$ $=\operatorname{div}(a(u) \operatorname{grad} u)$ с постоянным начальным условием и граннчным условием первого рода,-причем $a$ есть положительная аналитическая функция от $u$. ПІод некоторыми дополнительными предиоложениями относительно $u$ доказывается теорема единственности длля определения ноэффициента $a$.

The quasilinear parabolic differential equation $u_{t} \doteq \operatorname{div}(a(\dot{u}) \operatorname{grad} u)$ with a constant initial condition and a boundary condition of the first kind is considered where $a$ is a positive analytic function of $u$. Under some additional assumptions on $\dot{u}$ a uniqueness theorem for the determination of the coefficient $a$ is proved.

\section{Introduction}

We use the following notations. $D$ is a bounded region of the $n$-dimensional Euclidean space $\mathbf{R}^{n}$ with a sufficiently smooth boundary $\partial D, T$ a positive number, $Z_{T}=D$ $. \times(0, T), \Gamma_{T}=\partial D \times\left[0, T^{\prime}\right)$. By $\bar{M}$ we denote the closure of a set $M . \subseteq \mathbf{R}^{n}$ or $M \leqq \mathbf{R}^{n+1}$. Points of $\mathbf{R}^{n}$ are denoted by $x=\left(x_{1}, x_{2}, \ldots, x_{n}\right), t$ is a real variable (timie) with $0 \leqq t \leqq T$. For points $P=(x, t), P^{\prime},=\left(x^{\prime}, t^{\prime}\right) \in Z_{T}$ we introduce the distance $d\left(P, P^{\prime}\right)=\left(\left\|x-x^{\prime}\right\|_{\mathbf{R}^{n}}^{2}+\left|t-t^{\prime}\right|\right)^{1 / 2}$. Using this metric we denote the space of all real functions which are uniformly Hölder continuous with the exponent $\alpha(0<\alpha \leqq 1)$, in $Z_{T}$ by $\bar{C}_{a}\left(Z_{T}\right)$ : By $\bar{C}_{2+a}\left(Z_{T}\right)$ we denote the space of all functions possessing uniformly Hölder continuous derivatives (exponent $\alpha$ ) up to the order 2 with respect to $x_{1}, \ldots, x_{n}$ and up to the order 1 with respect to $t$ in $Z_{T}$. For the precise definitions see $[3:$ p. 61 ] .

We.consider the boundary, value problem

$$
\left.\begin{array}{ll}
u_{t}(x, t)=\operatorname{div}\left(a(u(x, t)) \operatorname{grad} u\left(x^{\prime}, t\right)\right) & \text { in } Z_{T} \\
u(x, 0)=d(d \text { constant }) & \text { in } \bar{D} \\
u(x, t)=\psi(x, t) & \text { on } \Gamma_{T}^{\prime}
\end{array}\right\}
$$

with $\psi$ a given real function satisf ying the conditions

$$
\psi \in \dot{C}\left(\bar{\Gamma}_{T}\right), \quad-\psi(x, 0)=d \quad\left(x \in \partial \partial^{\prime} D\right) .
$$

Now we define

$$
v_{0}=\min \left\{d, \min _{\left(x, t, \bar{\Gamma}_{T}\right)} \psi(x, t)\right\}, \quad . v_{\mathbf{1}}=\max \left\{d, \max _{(x, t) \in \bar{\Gamma}_{T}} \psi(x, t)\right\} .
$$


We assume that $v_{0}<v_{1}$ and that $a=a(u)$ is a real function of the real variable $u$ which is analytic in an interval $\left[v_{0}{ }^{*}, v_{1}{ }^{*}\right]$ with $v_{0}{ }^{*}<v_{0}$ and $v_{1}<v_{1}{ }^{*}$. Further let $a(u)>0$ for all $u \in\left[v_{0}, v_{1}\right]$. In this case we say that $a$ is of the class $A$ or $a \in A$. Let the real function $u$ satisfy the conditions

$$
u \in C\left(\bar{Z}_{T}\right) \cap \bar{C}_{2+a}\left(Z_{T}\right), \quad u_{x_{i}} \in C\left(\bar{Z}_{T}\right) \quad(i=1, \ldots, n) ; \quad \Delta \dot{u} \in C\left(\bar{Z}_{T}\right)
$$

Lastly we assume that, under the stated assumptions, for every $a \in A$ there exists a unique solution $u$ of the boundary value problem (1.1) which fulfils the condition (1.3). We denote this solution by $u=u(a, x, t)$. Using a maximum principle one obtains that $v_{0} \leqq u(a, x, t) \leqq v_{1}$ for all $(x, t) \in Z_{T}$ and $a \in \cdot A$.

In this paper we consider the inverse problem of determining the coefficient $a$ if $u\left(a, x_{0}, t\right)$ is known in an interior point $x_{0} \in D$ for all $t \in[0, T]$, and we prove a uniqueness theorem for this problem. The paper is closely related to that of S. Dü MMEL [2] where the mentioned inverse problem is considered for the more simple equation $u_{t}=a(u) \Delta u$. The special case where $a(u)$ is constant can be found in S. DüMmeL

[1]. The equation $u_{t}=\operatorname{div}(a(u) \operatorname{grad} u)$ is investigated by $\mathrm{S}$. MeÝr $[5,6]$ for $a(u)=b\left(u-v_{0}\right)^{l}+c(b, c$ constant, $l$ natural number $)$. The last equation with additional information about $u$ on the boundary of $D$ can be found in some other papers, e.g. in N. V. Mozylev [7]. For further references see [2].

\section{Some lemmas}

In this section we shall state some lemmas which will be needed in the proof of the uniqueness theorem. Let $a_{1} \in A$ and $u_{1}, u_{2} \in \vec{C}_{2+a}\left(Z_{T}\right)$. We define functions $f_{1}$ and $f_{2}$ by

$$
\begin{aligned}
& f_{1}(x, t)= \begin{cases}\frac{a_{1}\left(u_{1}(x, t)\right)-a_{1}\left(u_{2}(x, t)\right)}{u_{1}(x, t)-u_{2}(x, t)} & \text { if } u_{1}(x, t) \neq u_{2}(x, t) \\
a_{1}^{\prime}\left(u_{2}(x t)\right) & \text { if } u_{1}(x, t)=u_{2}(x, t)\end{cases} \\
& f_{2}(x, t)= \begin{cases}\frac{a_{1}{ }^{\prime}\left(u_{1}(x, t)\right)-a_{1}{ }^{\prime}\left(u_{2}(x, t)\right)}{u_{1}(x, t)-u_{2}(x, t)} & \text { if } u_{1}(x, t) \neq u_{2}(x, t) \\
a_{1}{ }^{\prime}\left(u_{2}(x, t)\right) & \text { if } u_{1}(x, t)=u_{2}(x, t)\end{cases}
\end{aligned}
$$

Lemma 1: One has $f_{1}, f_{2} \in \bar{C}_{\alpha}\left(Z_{T}\right)$.

This lemma can-be proved as in [7].

We introduce the following notations:

$$
k_{-}=\left\{\begin{array}{l}
k / 2 \text { for even } k \\
(k-1) / 2 \text { for odd } k,
\end{array} \quad k_{+}=\left\{\begin{array}{l}
k / 2 \text { for even } k \\
(k+1) / 2 \text { for odd } k
\end{array}\right.\right.
$$

Let $g_{1}, g_{2}$ be real analytic functions in an interval $\left[c_{1}, c_{2}\right]$. By $W(u)$ we denote Wronski's determinant

$$
W(u)=\left|\begin{array}{lc}
g_{1}(u) & g_{2}(u) \\
g_{1}^{\prime}(u) & g_{2}^{\prime}(u)
\end{array}\right|
$$


Lemma 2: The derivatives $W^{(k)}(k=1,2, \ldots)$ of $\dot{W}$ are given by

$$
\begin{aligned}
W^{(k)}= & \left|\begin{array}{ll}
g_{1} & g_{2} \\
g_{1}{ }^{(k+1)} & g_{2}{ }^{(k+1)}
\end{array}\right|+b_{1}\left|\begin{array}{ll}
g_{1}{ }^{\prime} & g_{2}{ }^{\prime} \\
g_{1}{ }^{(k)} & g_{2}{ }^{(k)}
\end{array}\right| \\
& +b_{2}\left|\begin{array}{ll}
g_{1}{ }^{\prime \prime} & g_{2}{ }^{\prime \prime} \\
g_{1}{ }^{(k-1)} & g_{2}{ }^{(k-1)}
\end{array}\right|+\cdots+b_{k-}\left|\begin{array}{ll}
g_{1}{ }^{(k-)} & g_{2}{ }^{(k-)} \\
\dot{g}_{1}{ }^{\left.(k+2)_{+}\right)} & g_{2}{ }^{\left.(k+2)_{+}\right)}
\end{array}\right|
\end{aligned}
$$

where $b_{1}=k-1$ and $b_{2}, \ldots, b_{k_{-}}$are real numbers.

The proof can be made by mathematical induction.

\section{A uniqueness theorém}

Under, the stated assumptions and some additional conditions we obtain that the inverse problem of the determination of the coefficient $a$ has at most one solution, if we suppose that $a(d)$ is known.

Theorem:'For all $a \in A$ let $u(a, \cdot, \cdot)$, be the solution of (1.1) satisfying the conditions (1.3) and in addition the condition

$$
u_{t}(a, x, t) \geqq 0 \quad\left((x, t) \in Z_{T} ; a \in A\right) .
$$

where the function $\psi$ fulfils the condition (1.2). Suppose that $x_{0} \in D$ and $h \in C^{1}([0, T])$. Furthermore let there exist a positive number $t_{0}$ such that $h^{\prime}(t)>0$ for all $t \in\left(0, t_{0}\right]$. Lasily let $a_{0}$ be a positive number. Then there is at most one $a \in A$ with $a(d)=a_{0}$ such that $u\left(a, x_{0}, t\right)=h(t)$ for all $t \in[0, T]$.

Proof: We suppose that there are two functions $a_{1}, a_{2} \in A$ with $a_{1}(d)=a_{2}(d)=a_{0}$ such that

$$
u\left(a_{1}, x_{0}, t\right)=u\left(a_{2}, x_{0}, t\right)=h(t) \text { for all } t \in[0, \dot{T}] .
$$

For brevity we set $u_{i}(x, t)=u\left(a_{i}, x, t\right)(i=1,2)$ and $u_{12}=u_{1}-u_{2}, a_{12}=a_{1}-a_{2}$. From

$$
\left(u_{i}\right)_{t}=\operatorname{div}\left(a_{i}\left(u_{i}\right) \operatorname{grad} u_{i}\right)=a_{i}\left(u_{i}\right) \Delta u_{i}+a_{i}{ }^{\prime}\left(u_{i}\right)\left(\operatorname{grad} u_{i}\right)^{2} \quad(i=1,2)
$$

we obtain a linear parabolic differential equation of second order for the function $u_{12}$ by elementary computations:

$$
\begin{aligned}
& \left(u_{12}\right)_{t}-a_{1}\left(u_{1}\right) \Delta u_{12}-a_{1}^{i}\left(u_{1}\right) \sum_{j=1}^{n}\left(\left(u_{1}\right)_{x_{j}}+\left(u_{2}\right)_{x_{j}}\right)\left(u_{12}\right)_{x_{j}} \\
& -\left[f_{1} \Delta u_{2}+f_{2}\left(\operatorname{grad} u_{2}\right)^{2}\right] u_{12}=\operatorname{div}\left(a_{12}\left(u_{2}\right) \operatorname{grad} u_{2}\right) \quad\left((\dot{x}, t) \in Z_{T}\right) .
\end{aligned}
$$

Moreover $u_{12}$ satisfies the conditions

$$
u_{12}(x, 0)=0 \quad(x \in \bar{D}) \text { and } u_{12}(x, t)=0 \quad\left((x, t) \in \Gamma_{T}\right) \text {. }
$$

Because of $a \in A,(1.3)$ and Lemma 1 the assumptions of [4: $\S 4$, Theorem 3] are fulfilled. Using this theorem we obtain that there exists a unique solution of the initial boundary value problem (3.3), (3.4). This solution can be represented by Green's function $G$ of the operator of the differential equation (3.3). Consequently we have

$$
u_{12}(x, t)=\int_{0}^{t} \int_{D} G\left(x, t ; x^{\prime}, t^{\prime}\right) \cdot \operatorname{div}\left(a_{12}\left(u_{2}\left(x^{\prime}, t^{\prime}\right) \operatorname{grad} u_{2}\left(x^{\prime}, t^{\prime}\right)\right)\right) d x^{\prime} d t^{\prime}
$$


Because of (3.2) for the left-hand side of (3.5) there holds

$$
u_{12}\left(x_{0}, t\right)=u_{1}\left(x_{0}, t\right)-u_{2}\left(x_{0}^{\prime}, t\right)=0 \text { for all } t \in[0, T] .
$$

The function $a_{12}$ is analytic in the interval $\left[v_{0}^{*}, \dot{v}_{1}^{*}\right]$. From the identity theorem for' analytic functions it follows that either $a_{12}(u)=0$ for all $u \in\left[v_{0}, v_{1}\right]$, and we have the uniquenèss of the function $a$, or $a_{12}$ has at most finitely many zeros in $\left[v_{0}, v_{1}\right]$. We investigate the second case. Since $\partial u_{2} / \partial t \geqq 0$ in $\bar{Z}_{T}, u_{2}(x, \cdot)$ is monotone increasing for fixed $x \in \bar{D}$. Thus $d=v_{0}$, and we have $a_{1}\left(v_{0}\right)=a_{2}\left(v_{0}\right)$. Hence $v_{0}$ is a ,zero of the function $a_{12}$. By $w$ we denote the smallest of these zeros which is greater than $v_{0}$, if such a zerọ exists. If such a zero does not exist we set $w=v_{1}$. Then, for all $u$ with $v_{0}<u<w$, either $a_{12}^{\prime}(u)>0$ or $a_{12}(u)<0$. We consider the first case. 'The second case can be treated analogously. In [2] it was proved that there exists a $T_{0}>0$ such that $a_{12}\left(u_{2}(x, t)\right)$ does not change the sign for all $x \in \bar{D}$ and all $t \in\left(0, T_{0}\right)$. Now we define $T_{0}{ }^{*}=\min \left\{t_{0}, T_{0}\right\}$. Using $h^{\prime}(t)>0\left(t \in\left(0, t_{0}\right]\right)$ ive can see as in [2] that there exists a neighborhood $S_{\varepsilon}\left(x_{0}\right)$ of $x_{0}$ and an interval $\left(t_{1}, t_{2}\right) \subset\left[0, T_{0}^{*}\right]$ such that

$$
\left(u_{2}\right)_{t}(x, t)>0, \quad . \quad u_{2}(x, t)>v_{0}, \quad\left((x, t) \in B_{T_{0}} \cdot=S_{\varepsilon}\left(x_{0}\right) \times\left(t_{1}, t_{2}\right)\right) .
$$

From this we obtain that

$$
a_{12}\left(u_{2}\right)>0 \text { and } a_{2}\left(u_{2}\right) \Delta u_{2}+a_{2}^{\prime}\left(u_{2}\right)\left(\operatorname{grad} u_{2}\right)^{2}=\left(u_{2}\right)_{t}>0
$$

for all $(x, t) \in B_{T_{0}^{*}}$. Let $W(u)$ be the determinant (2.1) with $\dot{g}_{1}=a_{2}$ and $g_{2}=a_{12}$. Then we obtain

$$
\begin{aligned}
\operatorname{div}\left(a_{12}\left(u_{2}\right) \operatorname{grad} u_{2}\right) & =a_{12}\left(u_{2}\right)^{\prime} \Delta u_{2}+a_{12}^{\prime}\left(u_{2}\right)\left(\operatorname{grad} u_{2}\right)^{2} \\
& >\frac{W\left(u_{2}\right)}{a_{2}\left(u_{2}\right)}\left(\operatorname{grad} u_{2}\right)^{2} \quad\left((x, t) \in B_{T_{0}}{ }^{*}\right) .
\end{aligned}
$$

Now we prove that there exists a real number $w_{1}>0$ such that $W(u)>0$ for all $u \in\left(v_{0}, \dot{v}_{0}+w_{1}\right)$. The function $a_{12}=a_{12}(u)$ is analytic in a neighborhood of $v_{0}$ and $a_{12}\left(v_{0}\right)=0$. Either the derivatives $a_{12}^{(k)}\left(v_{0}\right)=0$ for every $k$, and we have $a_{1}(u)=a_{2}(u)$ in a neighborhood of $v_{0}$; or there exists a natural number $m$ such that

$$
a_{12}^{(k)}\left(v_{0}\right)=0 \quad(k \in\{0,1, \ldots, \dot{m}\}) \quad \text { and } \quad a_{12}^{(m+1)}\left(v_{0}\right) \neq 0 .
$$

We choose $u$ such that $v_{0}<u<w$. Then by Taylor's theorem we obtain, for sume $\xi \in\left(v_{0}, u\right)$,

$$
a_{12}(u)=\frac{a_{12}^{(m-1)}(\xi)\left(u-v_{0}\right)^{m+1}}{(m+1) !}, \quad a_{12}^{(m+1)}(\xi)=\frac{(m+1) ! a_{12}(u)}{\left(u-v_{0}\right)^{m+1}}>0
$$

and, because of $(3.9)$;

$$
a_{12}^{(m+1)}\left(v_{0}\right)^{\circ}=\lim _{u \rightarrow v_{0}} a_{12}^{(m+1)}(\xi)>0 .
$$

$W=\dot{W}(u)$ is also an analytic function and from (2.2) and (3.10) we obtain for $m \geqq 1$

$$
\begin{aligned}
& W^{(k)}\left(v_{0}\right)=0 . \quad(k \in\{0,1, \ldots, m-1\}), \\
& \dot{W^{(m)}\left(v_{0}\right)=a_{2}\left(v_{0}\right) \dot{a}_{12}^{(m+1)}\left(v_{0}\right)>0 .} .
\end{aligned}
$$

For $m=0$ there holds $\hat{W}^{(0)}\left(v_{0}\right)=W\left(v_{0}\right)>0$. Again using Taylor's theorem, (3.7), (3.11) and the continuity of $W^{(m)}(u)$ in $\left[v_{0}, v_{1}\right]$ one can easily see that there exists 
a $w_{1}>v_{0}$ such that

$$
W\left(u_{2}\right)=\frac{W^{(m)}(\xi)\left(u_{2}-v_{0}\right)^{m}}{m !}>0 \quad\left(u_{2} \in\left(v_{0}, v_{0}+v_{1}\right)\right) .
$$

As in [2] it can be proved that there exists a $T_{1}>0$ such that $W\left(u_{2}(x, t)\right)$ does not change the sign for all $(x, t) \in \bar{Z}_{T_{1:}}$ We define $T_{1}^{*}=\min \left\{T_{0}^{*}, T_{1}\right\}$ and $B_{T_{1}}{ }^{*}$ similarly as the set $B_{T_{0} \cdot \text {. Both }} B_{T_{0}^{*}}$ and $B_{T_{i}}^{*}$ can be chosen in such way that $B_{T_{1}}$ * $\subseteq B_{T_{0} *}$ Then fromi (3.8) and (3.12) we obtain

$$
\operatorname{div}\left(a_{1 \dot{2}}\left(u_{2}\right) \operatorname{grad} u_{2}\right)>\frac{W\left(u_{2}\right)}{a_{2}\left(u_{2}\right)}\left(\operatorname{grad} u_{2}\right)^{2} \geqq 0, \quad\left((x, t) \in B_{T_{1}}\right) .
$$

Moreover for all $(x, \dot{t}) \in Z_{T_{1}} \cdot$ we have $a_{12}\left(u_{2}(x, t)\right) \geqq 0$ and $W\left(u_{2}\right) \geqq 0$. Then if we repeat the above consideration it follows from (3.1) that

$$
\operatorname{div}\left(a_{12}\left(u_{2}\right) \operatorname{grad} u_{2}\right) \geqq \frac{W\left(u_{2}\right)}{a_{2}\left(u_{2}\right)}\left(\operatorname{grad} u_{2}\right)^{2} \geqq 0 \quad\left((x, t) \in Z_{T_{1}^{*}}\right) .
$$

Lastly we have (see [3: p. 83])

$$
G\left(x_{0}, T_{1}^{*}, x, t\right)>0 \quad\left((\dot{x}, t) \in Z_{T_{1}^{*}}\right) .
$$

Now from $\cdot(3.13)-(3.15)$ we obtain

$$
\int_{0}^{T_{1}^{*}} \int_{D} G\left(x_{0},-T_{1}^{*}, x^{\prime} ; t^{\prime}\right) \operatorname{div}\left(a_{12}\left(u_{2}\left(\dot{x^{\prime}}, t^{\prime}\right)\right) \operatorname{grad} u_{2}\left(x^{\prime}, t^{\prime}\right)\right) d x^{\prime} d t^{\prime}>0 .
$$

But this is a contradiction to (3.5) and (3.6), and thus $a_{1}(u)=a_{2}(u)$ for all $u \in\left[v_{0}, v_{1}\right]$

Remark: If we consider the class of coefficients $a$ with the property: $a$ is an analytic function in the interval $\left[v_{0}^{*}, v_{1}^{*}\right], a(u)>0$ and $a^{\prime}(u)<0$ in the interval $\left[v_{0}, v_{1}\right]$, then the proof of the uniqueness theorem is very simple.

In the uniqueness theorem we have used the supposition (3.1). In the following proposition, we shall give sufficient conditions which imply this relation.

Proposition: Let $a \in A$ and $u$ be the unique solution of the boundary value problem. (1.1) satisfying the conditions

$$
u_{t} \in C\left(\bar{Z}_{T}\right) \cap \bar{C}_{2+a}\left(Z_{T}\right), \quad, u_{x_{i}} \in C\left(\bar{Z}_{T}\right) \quad(i=1, \ldots, n), \quad \Delta u \in C\left(\bar{Z}_{T}\right) .
$$

Suppose that the boundary function $\psi$ fulfils (1.2) and in addition $\psi(x, \cdot)^{\prime} \in C^{1}([0, T])$, $\psi_{t}(x, 0)=0$ for all $x \in \partial D, \psi_{t}(x, t) \geqq 0$ for all $(x, t) \in \Gamma_{T}$. Then we have $u_{t}(x, t) \geqq 0$ for all $(x, t) \in \bar{Z}_{T}$.

Proof: Set $u_{\imath}^{\prime}=w$. From (3.16) it follows that $w \in C\left(\bar{Z}_{T}\right) \cap \bar{C}_{2+a}\left(Z_{T}\right)$, and we have

$$
\begin{aligned}
w_{t}= & a(u) \Delta w+2 a^{\prime}(u) \operatorname{grad} u \operatorname{grad} \dot{w} \\
& +\left[\dot{a}^{\prime}(u) \Delta u+a^{\prime \prime}(u)(\operatorname{grad} u)^{2}\right] w \cdot \operatorname{in} Z_{T},
\end{aligned}
$$

$\dot{w}(x, 0)=0$ in $\bar{D}, w(x, t)=\psi_{t}(x, t)$ on $\Gamma_{T}$. The functions $a(u), a^{\prime}(u), a^{\prime \prime}(u), u_{x_{1}}, \ldots, u_{x_{n}}$ and $\Delta u$ are bounded in $Z_{T}$. Hence the coefficients in the differential equation (3.17) are alșo bounded in $Z_{T}$. On the boundary $\Gamma_{T} \cup \bar{D}$ we have $w(x, t) \geqq 0$. Using a 'maximum principle [4: p. 8] we obtain $\dot{u}_{t}(x, t)=w(x, t) \geqq 0$ for all $(x, t) \in \bar{Z}_{T}$ 


\section{REFERENCES}

[1] DüMmel, S.: Ein inverses Problem für die Wärmeleitungsgleichung. Wiss. Z. Techn. Hochsch. Karl-Marx-Stadt 23 (1981), 355-359.

[2] Dịnmel, S.: Uniqueness Theorems for the Determination of a Coefficient in a Quasilinear Parabolic Equation. Z. Anal. Anw. ó (1986), 419-424.

[3] Friedmann, A.: Partial Differential Equations of Parabolic Type. Englewood Cliffs NJ: Prentice Häll 1964.

[4] Ильин, А. М., КАлмшнинов, А. С., и О. А. Олейиик: Јинейные уравнения второго порядка параболического типа:.Успехи мат. наук. 17 (105) (1962) 3, 3-146.

[5] Meyer, S.: Die Existenz einer Lösung für ein inverses Problem der Wärmeleitungs. gleichung im quasilinearen Fall. Wiss. Z. Techn. Hochsch: Karl-Marx-Stadt 26 (1984), $259-264$.

[6] Meyer, S.: Die Eindeutigkeit der Lösung eines inversen Problems für die Wärmeleitungsgleichung im quasilinearen Fall. Wiss. Z. Techn. Hochsch. Karl-Marx-Stadt 27 (1985), $117-120$.

[7] Музылев, Н. В.: Теоремы единственности длля некоторых обратных задач теплопроводности. Ж. выч. мат. и мат. физ. 20 (1980), 388-400.

Manuskripteinging: 30.01.1987

VERFASSER: :

Prof. Dr. Stegrated Dümmel und Dr. Sybille Handorock-Meyer

Sektion Mathematik der Technischen Hòchschule

DDR - 9010 Karl-Marx-Stadt, PSF 964 